\title{
Satellite-based detection of Canadian boreal forest fires: development and application of the algorithm
}

\author{
Z. LI $\dagger^{*}$, S. NADON $\ddagger$ and J. CIHLAR $\dagger$ \\ $\nmid$ Canada Centre for Remote Sensing, 588 Booth, Ottawa, Ontario, Canada, \\ K1A OY7 \\ łEnvironment Canada, Ottawa, Ontario, Canada, K1A OH3
}

(Received 27 July 1998; in final form 4 June 1999)

\begin{abstract}
This study presents a comprehensive investigation of fires across the Canadian boreal forest zone by means of satellite-based remote sensing. A firedetection algorithm was designed to monitor fires using daily Advanced Very High Resolution Radiometer (AVHRR) images. It exploits information from multichannel AVHRR measurements to determine the locations of fires on satellite pixels of about $1 \mathrm{~km}^{2}$ under clear sky or thin smoke cloud conditions. Daily fire maps were obtained showing most of the active fires across Canada (except those obscured by thick clouds). This was achieved by first compositing AVHRR scenes acquired over Canada on a given day and then applying the fire-detection algorithm. For the fire seasons of 1994-1998, about 800 NOAA/AVHRR daily mosaics were processed. The results provide valuable nation-wide information on fire activities in terms of their locations, burned area, starting and ending dates, as well as development. The total burned area as detected by satellite across Canada is estimated to be approximately 3.9, 4.9, 1.3, 0.4 and 2.4 million hectares in 1994, 1995, 1996, 1997 and 1998, respectively. The peak month of burning varies considerably from one year to another between June and August, as does the spatial distribution of fires. In general, conifer forests appear to be more vulnerable to burning and fires tend to grow larger than in deciduous forests.
\end{abstract}

\section{Introduction}

Quantitative information about the spatial and temporal distribution of fires is important for forest protection and in the management of forest resources. It is also indispensable to such disciplines as ecology, wildlife management and atmospheric chemistry (Levine 1991). Emissions of greenhouse gases and aerosols from fires are of great interest to climate change studies (Crutzen and Andreae 1990, Levine 1991). Beside changes in land cover as a result of burning, fires also affect terrestrialatmospheric interactions (Levine et al. 1995, Scholes 1995).

In the last decade, images from the Advanced Very High Resolution Radiometer (AVHRR) on board the National Oceanic and Atmospheric Administration (NOAA) series satellites were often employed to detect wild fires (Robinson 1991, Arino and Mellnotte 1995, Illera et al. 1995 ). While NOAA-AVHRR instruments were designed mainly for weather surveillance and sea surface temperature management, their

*Corresponding author; e-mail: li@ccrs.nrcan.gc.ca 
capability for detecting fires has been exploited as well. Studies on the detection and environmental and climatic impact of tropical fires have made the most extensive use of AVHRR data (Kaufman et al. 1990, Malingreau 1990, Justice et al. 1996). It was estimated that tropical fires around the world destroyed about $15 \times 10^{6} \mathrm{~km}^{2}$ of forests in the last decade (Singh 1993). Only a few handful of studies were reported on the detection of boreal forest fires using AVHRR data (Flannigan and Vonder Haar 1986, Cahoon et al. 1994, Li et al. 1997).

The total burned area in the world's boreal forests remains largely unknown (Setzer and Malingreau 1996). The lack of information hinders our ability to close the global carbon budget because the boreal biome covers an immense area where fire is a significant, if not a dominant, mechanism for releasing surface carbon stocks to the atmosphere (Sellers et al. 1995). Therefore, monitoring boreal forest fires is critical to evaluating their contribution to the atmospheric stock of greenhouse gases and aerosols, which are two major factors altering the course of anthropologic climate change. On the other hand, fire occurrence may serve as an indicator of climate change. While an individual fire event is random, the trend of fire activity over a large area in the long run is strongly affected by the climatic regime.

Therefore, our study on forest fires has both practical and research objectives: near real-time fire monitoring and acquiring a consistent fire database in Canada; and estimation of greenhouse and aerosol emissions and studying the relation/ interaction between climate change and fire activity. This study is an extension of a preliminary investigation by Li et al. (1997) on monitoring boreal forest fires using AVHRR satellite data. In that study, a fire-detection algorithm for use with NOAA-11 AVHRR data was developed and validated. The previous study area was limited to the Boreal Ecosystems Atmosphere Study (BOREAS) (Sellers et al. 1995) region of $1200 \times 1200 \mathrm{~km}^{2}$. The total area of fires detected by satellite agreed well with a ground-based estimate by fire agencies. In the present study, the same algorithm is applied to process all single-day AVHR R scenes acquired by NOAA-11 throughout the fire season of 1994 covering the entire Canadian landmass. The algorithm is, however, found to generate too many false fires when applied to the AVHRR images acquired by NOAA-14. Considerable efforts were therefore devoted to develop a new algorithm for use with NOAA-14 AVHRR data. The new algorithm was used to process AVHRR images obtained from 1995-1998 across Canada. The results of fire detection are presented in this paper. In a companion paper ( $\mathrm{Li}$ et al. 2000), the performance of the algorithm in mapping burnt area is evaluated in comparison to fire polygon data acquired by fire agencies.

The following section describes the data used in the study. Section 3 is concerned with the development and evaluation of a satellite fire-detection algorithm. An analysis of fire statistics obtained across Canada from 1994 to 1998 is presented in $\S 4$, and $\S 5$ summarizes the results.

\section{Data}

This study makes use of AVHRR images from NOAA-11 in 1994 and from NOAA-14 from 1995 to 1998. The local overpass time of NOAA-11 in Canada was around 15:45 with a viewing geometry close to the principal plane, i.e. the AVHRR sensor scanned the earth in either backward or forward scattering direction (Li et al. 1997). NOAA-14 has an earlier overpass time (13:00 LT in 1995 and somewhat later in subsequent years) with a viewing plane $45^{\circ}$ relative to the principal plane. After receiving the AVHRR data at the Prince Albert station receiving station in 
Saskatchewan, they were radiometrically calibrated and geometrically referenced using the geocoding and compositing (GEOCOMP) AVHRR data processing system (Robertson et al. 1992). The calibration for visible (channel 1) and near-infrared (channel 2) measurements of AVHRR/NOAA-11 employs time-dependent offset and gain values derived by Cihlar and Teillet (1995), while those for NOAA-14 were based on values recommended by Rao and Chen (1996). The thermal AVHRR channels (3-5) were calibrated using on-board blackbody reference. Pixel locations were first computed by an orbit model that takes into account spacecraft orbit, velocity, attitude and altitude, earth rotation and curvature, and then fine-tuned with reference to the ground control points determined from high resolution Landsat image chips. An overall registration accuracy of less than $1 \mathrm{~km}$ can be achieved with a sufficient number of ground control points available under clear conditions (Cihlar et al. 1997).

A small amount of AVHRR data from NOAA-14 was used for the development of the fire-detection algorithm. They consist of single-day AVHRR scenes over a region of $1200 \times 1200 \mathrm{~km}^{2}$ in northern Manitoba and Saskatchewan around the study region of the BOREAS where many forest fires occurred (Li et al. 1997). Besides, this region is representative of the boreal biome. Through human inspection of the satellite images, fires can be visually identified by co-location of the hot spots on channel 3 images and the associated smoke plume patterns on channel 1 (Setzer and Malingreau 1996, Li et al. 1997). A smoke plume usually shows conical or bending shape with a vortex over its origin. The inspection was facilitated by exploiting various functions of image enhancement such as linear/nonlinear stretching available from an image processing software (PCI). We have examined a large number of AVHRR scenes to obtain fire masks as a training database for the development of a fire-detection algorithm.

\section{Algorithm}

The fire-detection algorithm is based on the framework of Kaufman et al. (1990) with modifications for the NOAA-14/AVHRR sensor. In addition, new tests are introduced to cope with the special environment and burning conditions of the boreal ecosystem. The algorithm consists of two major steps: marking potential fires and removing false fires. Both steps encompass threshold tests. All the tests are optimized to both detect real fires and eliminate as many false fires as possible. While the majority of tests were proposed previously, the threshold values were chosen following a trial-and-error approach based on the fire training dataset. Histogram analyses of reflectance and brightness temperature corresponding to burning and nonburning pixels proved to be an effective means of obtaining optimized threshold values.

\subsection{Identifying potential fire pixels}

Following the pioneering work of Flannigan and Vonder Haar (1986) on automatic detection of fires using AVHRR data, numerous investigations have been conducted. Most have employed a threshold test based on the brightness temperature of AVHRR channel 3. This marks all potential fires not obscured by thick clouds by identifying the hot spots, i.e. pixels with brightness temperature $\left(T_{3}\right)$ higher than a certain value. According to the Planck's Law, AVHRR channel 3, with a central wavelength around $3.7 \mu \mathrm{m}$, receives maximum radiative energy from objects emitting at temperatures around $800 \mathrm{~K}$. This temperature is close to the temperature 
for burning biomass (Kennedy et al. 1994). However, since the AVHRR sensor was not designed for fire detection, it loses sensitivity at such high temperatures. For the AVHRR onboard NOAA-14, channel 3 becomes saturated at $T_{3} \approx 320 \mathrm{~K}$. Nevertheless, it still proves to be the most useful AVHRR channel for fire detection as the brightness temperature for most non-fire pixels is usually significantly lower. In practice, thresholds less than the saturation temperature are often used for two reasons. First, wild fires have a large range of burning temperature ranging from lower than $500 \mathrm{~K}$ to higher than $1000 \mathrm{~K}$ and they also have a variable fraction of burning area within a pixel. To allow for the detection of all fires, a lower threshold value is needed. Second, Setzer and Verstraete (1994) identified an engineering design problem in the on-board processing of channel 3 output signal for NOAA-11. They found that signals greatly exceeding the saturation limit are assigned values below the saturation limit. As a result, targets that are extremely hot can have a brightness temperature lower than $320 \mathrm{~K}$.

A brightness temperature of $T_{3}=315 \mathrm{~K}$ was chosen in this study. This threshold captures nearly all real fires in clear or thin-cloud covered regions, as confirmed by the fire training database. On the other hand, it also leads to far too many false fire pixels. These false identifications stem from the limitations of channel 3 such as sunglint effect, reflective soils, pixel overlap, sensor degradation, etc. (Setzer and Malingreau 1996). Sunglint is the most serious problem encountered in our analysis due to the presence of many lakes and rivers distributed throughout the Canadian Shield. For NOAA-11 that has view geometry near the principal plane, the problem can readily be resolved by avoiding the measurements made in forward scattering directions ( Li et al. 1997). For NOAA-14, however, this simple solution is no longer valid since its viewing plane is far away from the principal plane and because sunglint also occurs from cloud side in the backscattering direction. The subsequent tests are thus introduced to remove the false fire pixels.

\subsection{Removing false fires}

Kaufman et al. (1990) introduced three tests to eliminate false fires. We adopted these tests but tuned the threshold values. The first one uses the difference between channel 3 and channel 4 brightness temperatures $\left(T_{3}-T_{4}\right)$ to identify false fire pixels caused by a warm background. Some surface types (e.g. bare soil) can become warm enough to saturate channel 3 . Since the spectral window of channel 4 is located in the electromagnetic spectrum that has maximum radiative emission for the ordinary earth temperatures, $T_{3}-T_{4}$ is instrumental in discriminating these false fire pixels. In the case of biomass burning, channel 3 receives much more radiant energy than channel 4 and thus the value of $T_{3}-T_{4}$ is high (Kennedy et al. 1994, Dowty 1996). For the boreal forests, the threshold value for $T_{3}-T_{4}$ was set to $14 \mathrm{deg} \mathrm{K}$. All pixels with $T_{3}-T_{4}$ values lower than $14 \mathrm{deg} \mathrm{K}$ are considered false fire pixels caused by a warm background.

The second test employing channel 4 alone deletes false fires caused by highly reflective clouds. Radiance measured by channel 3 originates from both solar reflection and terrestrial emission. Reflection of the solar radiation by clouds can be large enough to also saturate channel 3. Since clouds usually have cold tops and thus low brightness temperatures, this test rejects marked fire pixels of $T_{4}$ less than $260 \mathrm{~K}$.

The third test is intended to eliminate more general bright-scene objects including both clouds and surface pixels. Note that fire hot spots have relatively low reflectance 
in channel $2\left(R_{2}\right)$ due to spewing ash and biomass consumption (Kennedy et al. 1994 ). Therefore, all fire pixels with $R_{2}>0.22$ are considered as false fires.

An additional threshold test is introduced to eliminate false fire pixels caused by thin cirrus clouds. In some cases, a combination of warm background and thin clouds can saturate channel 3 and negate the second test. Thin cirrus clouds have low $T_{4}$ and high $T_{3}$ because of reflection, leading to large values of $T_{3}$ and $T_{3}-T_{4}$. The additional test makes use of the difference between the two thermal channels of AVHRR, channels 4 and 5. The difference $T_{4}-T_{5}$ has been used to identify thin cirrus clouds, which is often referred to as the split window technique (Inoue 1987). This test is implemented in combination with a relaxed test using $T_{3}-T_{4}$. All hot spots with $T_{4}-T_{5} \geqslant 4.1 \mathrm{~K}$ and $T_{3}-T_{4}<19 \mathrm{~K}$ are removed as false fires; these thresholds have been established using the training database.

In addition to the above threshold tests, two special screenings are made. The first is designed in accordance with our objective of detecting forest fires. In Canada, forest fires are far more extensive and persistent than other types of fires. By restricting to forest fires, we can prevent certain problems. In particular, a large number of false fires caused by sunglint and soil reflection occur over water bodies, barren land, cropland and grassland. This test resorts to the use of a land cover classification at $1 \mathrm{~km}$ resolution derived from AVHRR data (Pokrant 1991). It includes 10 coarse land cover classes, namely, water, forests of four types (mixed wood, deciduous, conifer and transitional), Arctic/alpine tundra, barren lands, agricultural cropland, rangeland-pasture and cities. Only forest pixels are considered in the test, similar to Chuvieco and Martin (1994).

The second screening eliminates all single hot spot pixels, i.e. no neighbour pixels marked as fires. It copes with the problems caused by sub-pixel contamination. Due to the coarse pixel resolution and land cover classification, a designated forest pixel may contain a fraction of water body such as the edge of a lake, rendering a sunglint problem. Although NOAA-14's viewing geometry is away from the principal plane, sunglint can still be observed over a rough water surface. Also, sunglint from cloud side tends to affect isolated pixels where the Sun's position, the satellite viewing angle and the cloud surface conditions combine in the right geometry. This screening takes advantage of the fact that boreal forest fires usually spread much larger than a 1-km AVHRR pixel size. Most single-tagged hot spots turn out to be false fires. However, the screening has an adverse effect of eliminating small and initial-stage fires, which may be recovered by visual inspection of fire smokes though. Figure 1 presents a flowchart of the fire-detection algorithm.

The efficiency of each step of the algorithm is shown in table 1 that was computed from 24 training scenes of $1200 \mathrm{~km} \times 1200 \mathrm{~km}$ around the BOREAS region during 1995 fire season. For this training dataset, fires were identified by visual inspection of hot spots and smoke plumes in the absence of thick clouds. The results of the tests are given in terms of the number of true fires (NTF) retained and the number of false fires (NFF) removed in each test. Note that the efficiency of a specific test may depend on the sequence of the tests.

It follows from table 1 that after applying all the tests, the algorithm missed $11 \%$ of the true fire pixels and eliminated $99 \%$ of the false fires. In terms of fire events, the ratio of real fires missed would be smaller than the one given in table 1 , since a fire event usually consists of a cluster of fire pixels over a period of time. The test to remove single fire pixels causes very few real fires to be missed, yet it eliminates a large number of false fires. The most effective threshold test for eliminating false 


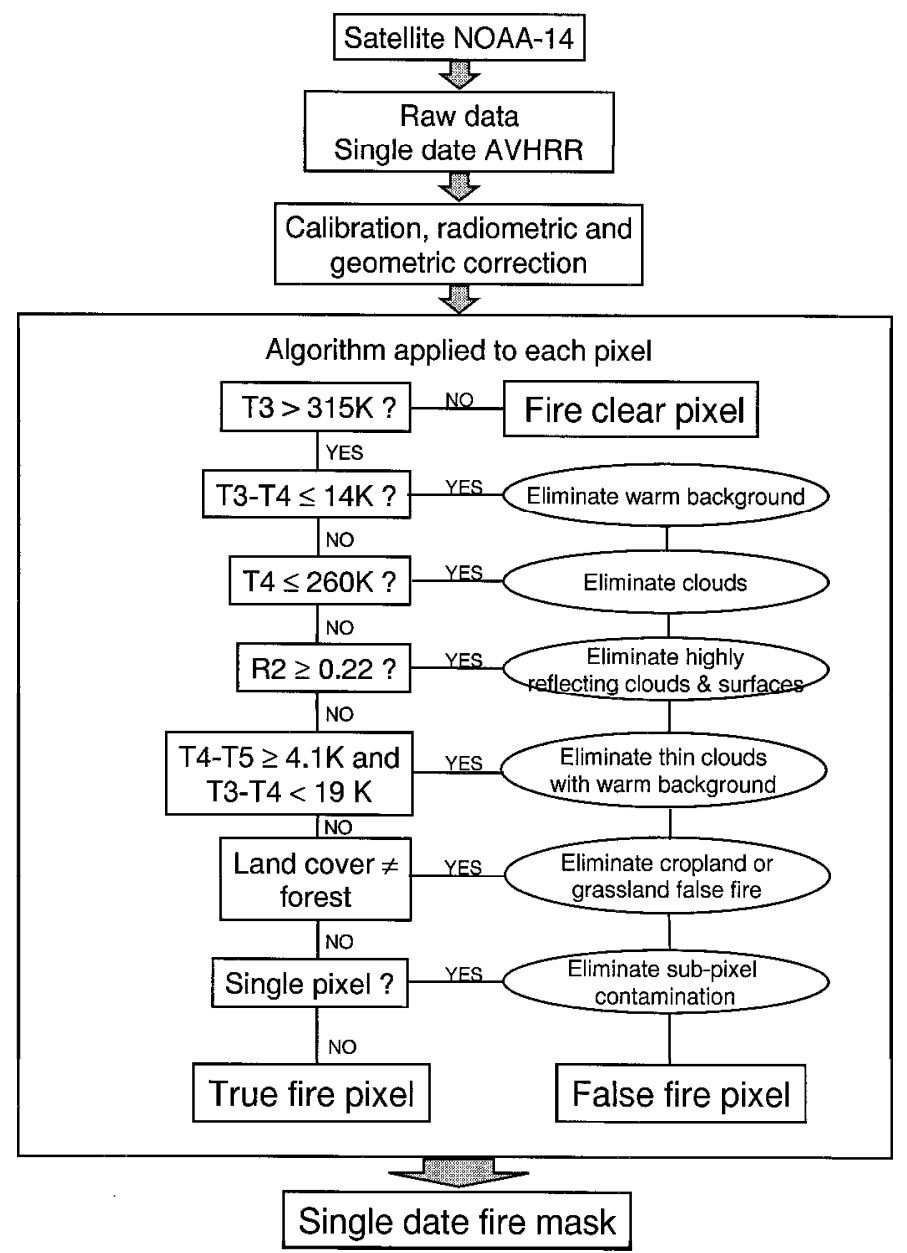

Figure 1. The flowchart of the fire-detection algorithm for use with NOAA-14 AVHRR data.

Table 1. Summary of the fire-detection tests and the statistics of their efficiency.

\begin{tabular}{lllrr}
\hline Test no. & \multicolumn{1}{c}{ Description } & \multicolumn{1}{c}{ Threshold } & \multicolumn{1}{c}{ NTF } & NFF \\
\hline 1 & Initial test & $T_{3}$ & 12569 & 168168 \\
2 & Eliminate warm background & $T_{3}-T_{4}$ & 12569 & 48855 \\
3 & Eliminate nonforest scenes & land cover & 12569 & 30511 \\
4 & Eliminate bright scenes & $R_{2}$ & 12442 & 5665 \\
5 & Eliminate cloud edges or thin clouds & $T_{4}-T_{5}$ and $T_{3}-T_{4}$ & 11307 & 2673 \\
6 & Eliminate cold clouds & $T_{4}$ & 11307 & 2673 \\
7 & Eliminate single fire pixels & & 11160 & 1828 \\
\hline
\end{tabular}

fires appears to be the difference between brightness temperatures in channels 3 and 4 , followed by a test based on channel 2 reflectance. While $14 \%$ of the 'fire pixels' that passed all the tests remain false fires, further reduction of these would lead to a larger number of real fires being missed.

Given the limitations in the signal content of AVHRR measurements pertaining 
to burning, a trade-off is necessary between the NTF retained and the NFF removed. This study has two goals: to develop a monitoring tool with a high probability for the detected pixels to be real active fires and to be able to use this tool to get an approximate overall estimation of fire statistics across Canada. It is thus a sound choice to use an algorithm leading to comparable rates of missing real fires and retaining false fires.

\section{Application}

The algorithm described above was applied to Canada-wide AVHRR mosaic images obtained every day from NOAA-14 in 1995, 1996, 1997 and 1998. The algorithm for processing NOAA-11 AVHRR data in 1994 was presented by Li et al. (1997).

A coast-to-coast AVHRR image mosaic is created by compositing about five scenes. Daily Canada-wide AVHRR mosaic is available from 1994 to 1998. Each mosaic contains data for the five AVHRR channels together with satellite view zenith (VZ), solar zenith (SZ) and relative azimuth (RA) angles and NDVI.

Figure 2 is an example of a fire mask derived from AVHRR images on 25 June 1995. Fire pixels are marked as red spots and the background is a false colour composite denoting land (green), blue (ocean), cloud (white) and smoke (yellow).

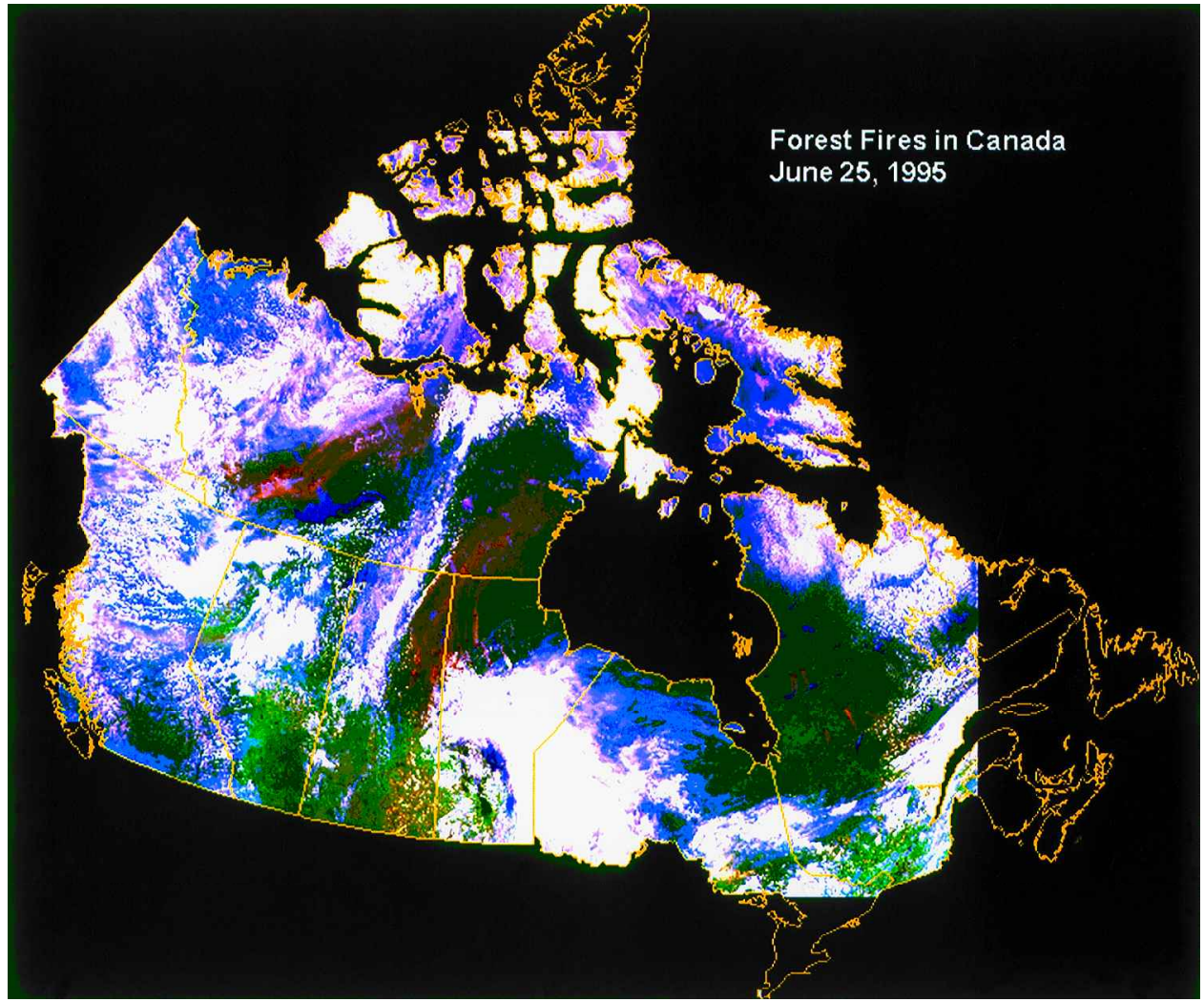

Figure 2. Forest fires detected on 25 June 1995 across Canada. The red dots are fire hot spots, superimposed on an AVHRR false colour composite image (green for vegetation, orange for smoke and white for clouds, blue for thin cloud over land). 
Broadly speaking, there are three major fire episodes, one located in Northwest Territories, one in a border region between Saskatchewan and Manitoba, and one in Quebec. Almost all of the detected fires are accompanied by smoke plumes, confirming their occurrence. Cloud cover is the primary limitation of the AVHRRbased fire detection technique, especially for real-time fire surveillance. It poses a less serious problem for obtaining seasonal fire statistics, since cloud cover changes quickly from day to day.

From the daily fire masks, annual composites of burned areas can be obtained. Figure 3 presents a composite of fire pixels detected between 1994 and 1998. Fire activity appears to be widespread and exhibits strong inter-annual and spatial variation. It is interesting to note that fires in remote areas, such as in the Northwest Territories and northern parts of western provinces, tend to grow larger than those in more populated areas such as southern Ontario and Quebec. This may be related to fire management practices, forest types and weather conditions. The northern forests consist primarily of conifers, while the southern ones are mainly deciduous. The conifer boreal forest stands are usually much drier than deciduous forests, facilitating fire growth. In addition, forest fire is a natural phenomenon in low-value northern forests. Therefore, little human intervention is normally exercised.

The spatial distribution of fires differs significantly among the years studied. In 1994, most fires occurred along the northern border of the boreal forest in western

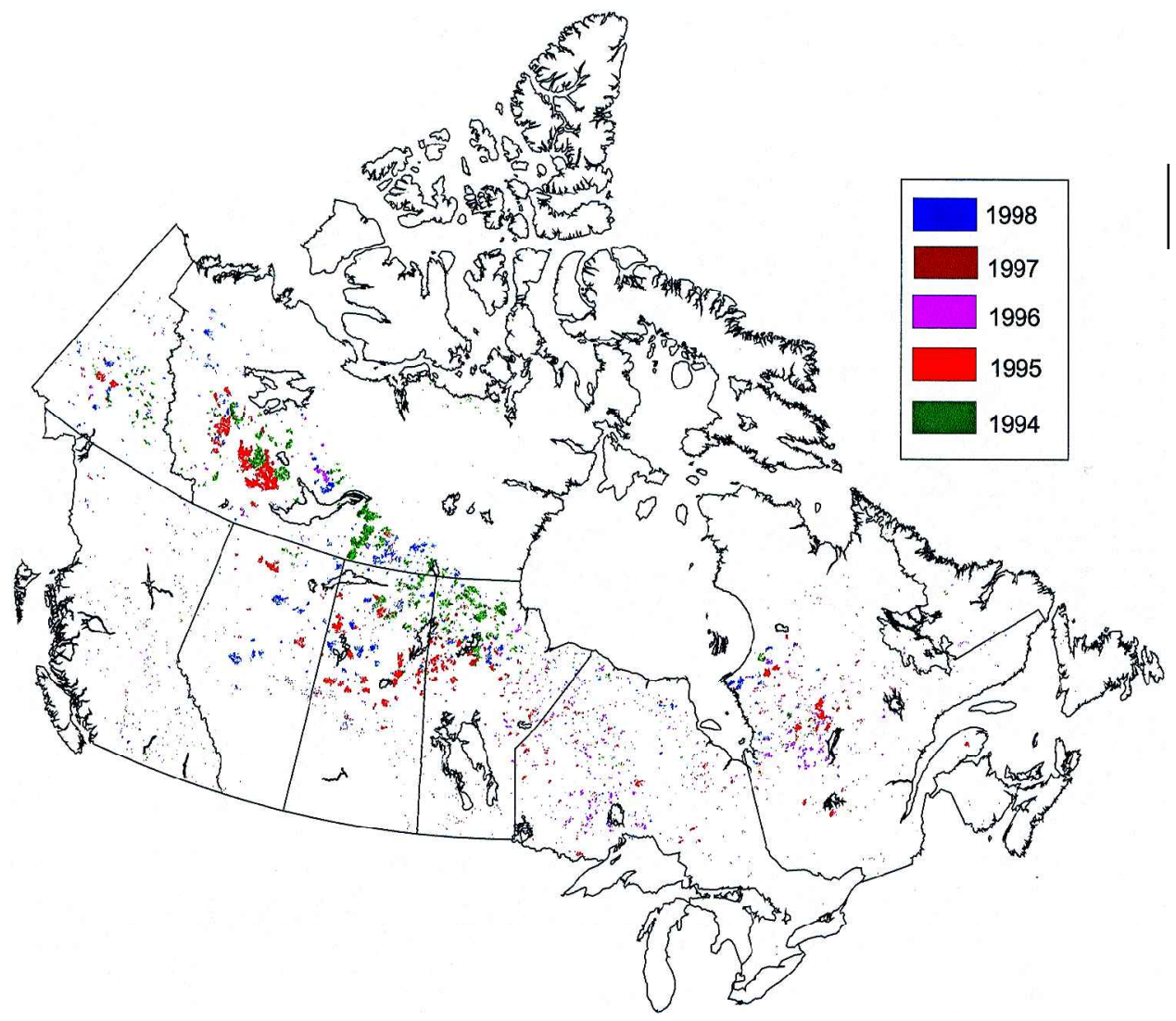

Figure 3. The distribution of fire spots across Canada in 1994-1998. 
Canada. In 1995, fires were widespread across the country. In 1996, fewer fires occurred generally confined to Ontario and Quebec. Even less forested area was burned in 1997, mostly in Quebec and Manitoba. Very few fire pixels from different years overlap. Browsing through the sequence of single-day fire images in 1995 indicates that fires usually travelled from west to east, as weather systems do.

The cumulative area of all fires across Canada is approximately 3.9, 4.9, 1.3, 0.4 and 2.4 million hectares for 1994, 1995, 1996, 1997 and 1998, respectively. In comparison, total burned area estimated by the Canadian Forest Service is 6.2, 6.6, 1.9, 0.6 and 4.7 million hectares (IFFN 1999), respectively for the above years. In comparing these numbers, one has to keep in mind that the areas shown in figure 3 represent the accumulated areas of the active fires detected when the satellite overpasses and when no thick clouds are present. Therefore, the underestimation of burnt area (about 35\% on average) is caused primarily by cloud cover and by the frequency of satellite observation (one per day). Another reason is that fire agencies may tend to overestimate the burnt area by omitting to record unburned islands lying within large burnt regions (Fraser et al. 1999). The higher level of underestimation in 1994 can also be partially caused by the NOAA-11 malfunction in early September, thus not allowing subsequent fires to be detected. A more detailed validation of this algorithm against ground-based observations is given Li et al. (2000).

Figure 4 shows the daily variation in total burned area from 1994 to 1997. It indicates that the period of active burning generally occurs from June to August with a peak in late July and early August in 1994, late June in 1995, middle June in 1996 and early June in 1997. Superimposed upon the seasonal trend is a substantial day-to-day variation. To a large extent, the daily fluctuations are caused primarily by the presence of clouds and secondarily by missing images. This conclusion is drawn from an extensive visual inspection of single-day images. The inspection helps determine the causes of the fluctuations that are classified into four categories: regular points (no significant artificial interruption), interruption by cloud cover, missing satellite scenes and the combination of the latter two. The majority of the dips do not correspond to real declines in fire activities. On the other hand, consecutive low fire counts are more likely real. Most of the false low fire counts appear to last for only 1 day. The seasonal trend of fire activities is more clearly evident in figure 5, which shows the monthly counts of fire pixels from 1994 to 1997. The most widespread burning occurred in June 1995.

In addition to the temporal statistics of all fires across Canada, information on the spatial spread of regional fires is also clearly conveyed by assigning different colours to the fire pixels detected during various periods of time. Figure 6 is an example of such an image for Northwest Territories in 1995 in which the fire occurrence is separated into 10-day periods. It is found that the largest fire was first detected between 1 and 10 June and expanded rapidly in all directions during the following 10 days and did not extinguish until the end of August. Other fires in this region have much shorter lifetimes.

\section{Summary}

This study provides the first comprehensive satellite surveillance of boreal forest fires across the Canadian landmass during a 5-year period. An algorithm designed to detect boreal forest fires was developed, and 5 years of AVHRR daily imagery data were processed to track fire development and to obtain fire statistics.

The fire-detection algorithm was designed on the basis of previous investigations 


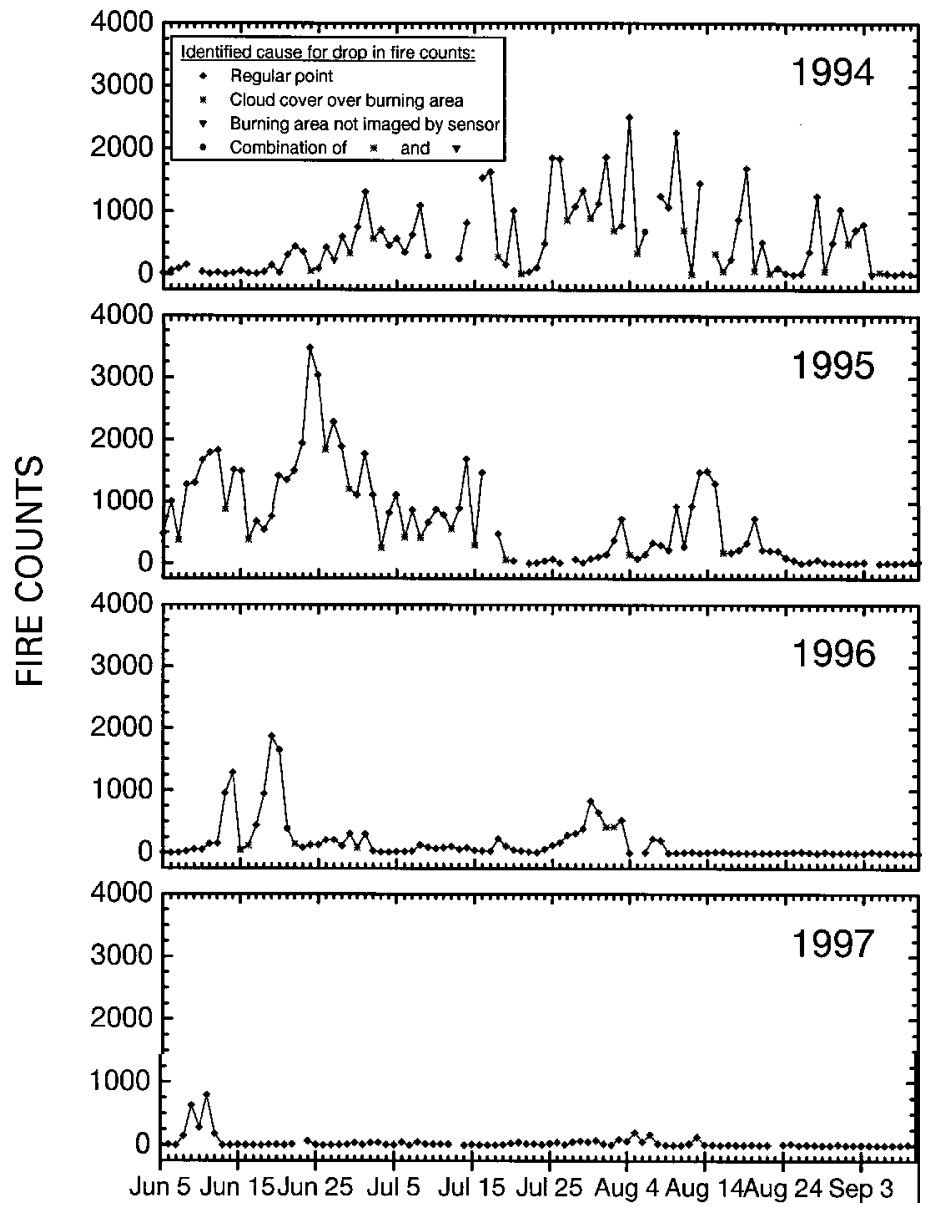

Figure 4. The daily variation of total number of fires from 1994 to 1997 with explanation for the cause of sudden drops.

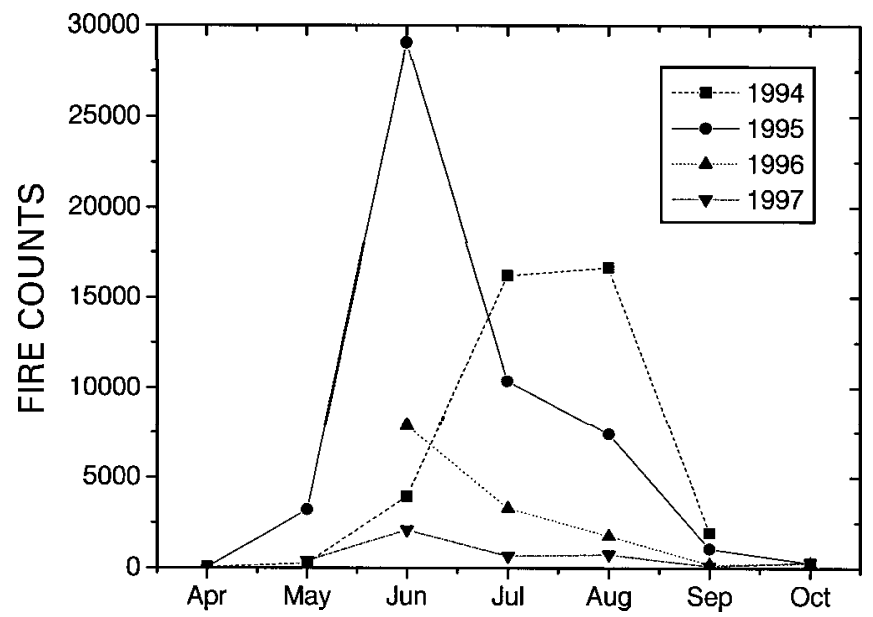

Figure 5. The monthly variation of total number of fires across Canada. 


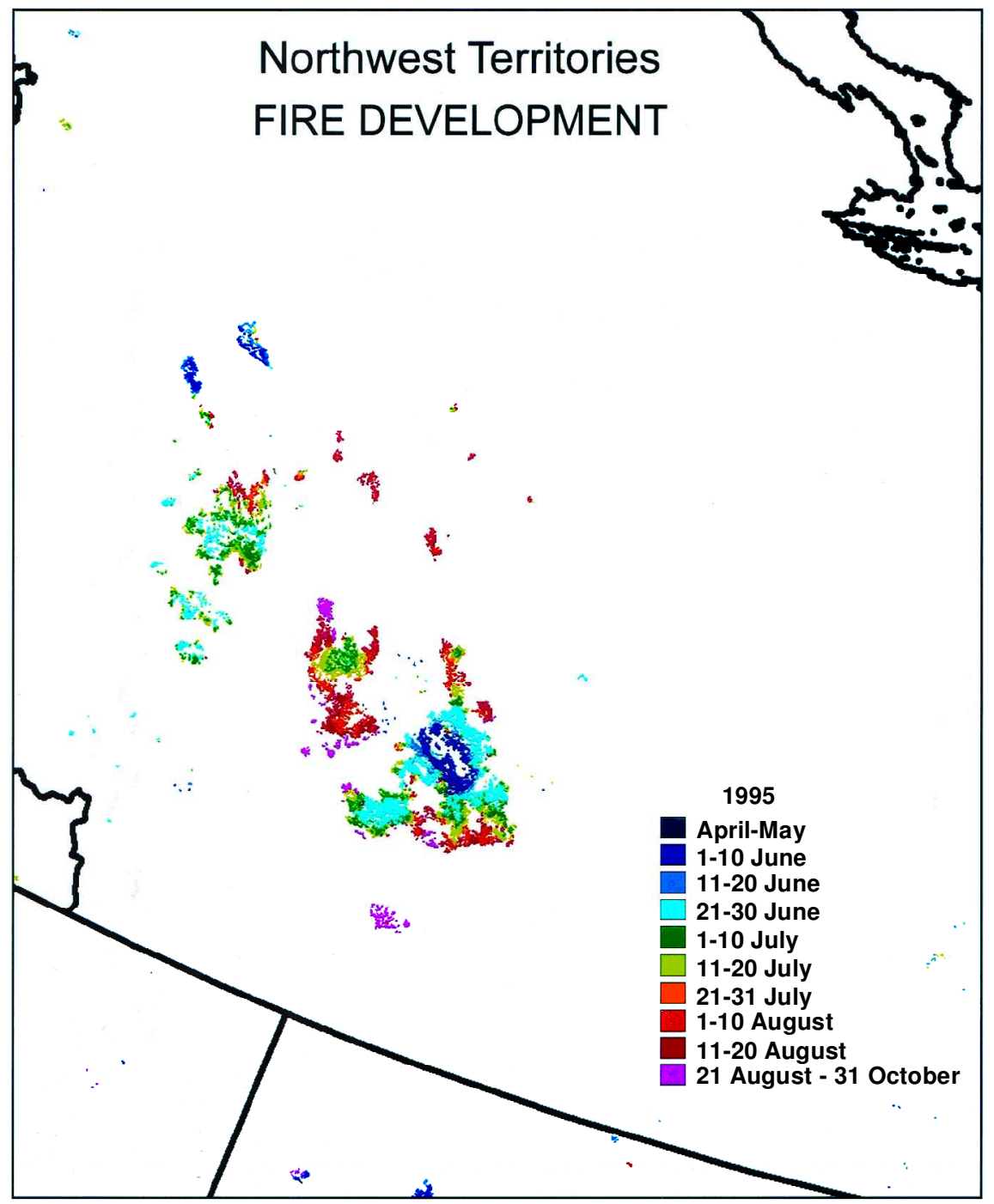

Figure 6. Fire development in Northwest Territories.

with special considerations to cope with the unique boreal environment. The algorithm consists of two basic steps, namely, marking all potential fire pixels and removing false fire pixels. This is done through a series of threshold tests, a land cover type test, and a test for the spatial contingency of fire pixels. The threshold values for the tests were optimized using a small volume of training dataset obtained by a visual analysis of AVHRR images. The algorithm is capable of capturing the majority of real fires in the absence of thick clouds.

The algorithm was applied to hundreds of Canada-wide AVHRR images from 1994 to 1998. Daily fire maps were obtained for the 5 years, from which monthly and seasonal fire statistics were computed. It was found that forest fires in Canada show strong inter- and intra-annual variations and that they are distributed nonuniformly. The total burned area detected in the 5 years differed by a factor of 
over 12, ranging from 0.4 million hectares in 1997 to 4.9 million hectares in 1995. These statistics are less than those obtained by conventional means of fire surveillance with an underestimation on the order of $35 \%$. The underestimation is mainly caused by cloud cover and limited satellite revisit frequency. The peak fire activity in a burning season occurs between June and August. Large fire clusters were found in the north-western conifer forests, while small fires scattered over the south-eastern deciduous forests.

This study lays a foundation for an operational satellite fire monitoring system to monitor fires on near real-time basis and to obtain a timely fire statistic across Canada. The system has the advantages of automatic operation, consistent data quality, cost-effective use, and rapid response over the vast territory of the Canadian boreal forest. The system was run very successfully during the fire season of 1998 . Daily fire images were generated and delivered to fire agencies, media and general public within $24 \mathrm{~h}$ of the reception of satellite data. The quality of near real-time detection is as good as shown in this paper. More and updated information can be found at the Canada Centre for Remote Sensing web page at http://www.ccrs.nrcan.gc.ca/ccrs/tekrd/rd/apps/em/cchange/canfire.html.

\section{Acknowledgments}

We would like to acknowledge the assistance of Mr Andrew MacPherson, Stephen Boles, and Robert Fraser in the development and application of the fire-detection algorithm. Devel-Tech Inc. in Saskatoon provided AVHRR mosaic images under a contract to CCRS.

\section{References}

Arino, O., and Mellnotte, J. M., 1995, Fire index atlas. Earth Observation, European Space Agency Quarterly, December.

Cahoon, D. R., JR, Stocks, B. J., Levine, J. S., Cofer, W. R., III, and Pierson, J. M., 1994, Satellite analysis of the severe 1987 forests fires in Northern China and Southeastern Siberia. Journal of Geophysical Research, 99, 18 627-18638.

Chuvieco, E., and Martin, M. P., 1994, A simple method for fire growth mapping using AVHRR channel 3 data. International Journal of Remote Sensing, 15, 3141-3146.

Cihlar, J., and Teillet, P. M., 1995, Forward piecewise linear calibration model for quasireal-time processing of AVHRR data. Canadian Journal of Remote Sensing, 21, 22-27.

Cihlar, J., Chen, J., and Li, Z., 1997, Seasonal AVHRR multichannel data sets and products for studies of surface-atmosphere interactions. Journal of Geophysical Research, 102, $29625-29640$.

Crutzen, P. J., and Andreae, M. O., 1990, Biomass burning in the tropics: impact on atmospheric chemistry and biogeochemical cycles. Science, 250, 1669-1678.

Dowty, P., 1996, The simulation of AVHRR data for the evaluation of fire-detection techniques. In Biomass Burning and Global Change, edited by J. S. Levine (Cambridge, Massachusetts: MIT Press), pp. 25-39.

Flannigan, M. D., and Vonder HaAR, T. H., 1986, Forest fire monitoring using NOAA satellite AVHRR, Canadian Journal of Forest Research, 16, 975-982.

Fraser, R., Z. LI, and Cihlar, J., 1999, A new technique for mapping burns: hot spot and NDVI differencing synergy (HANDS). Remote Sensing of Environment, in press.

IFFN, 1999, International forest fire news: Canada Report 1998, no. 20, 8 pp. (available from http://www.ruf.uni-freiburg.de/fireglobe/).

Illera, P., Fernandez, A., and Casanova, J. L., 1995, Automatic algorithm for the detection and analysis of fires by means of NOAA AVHRR images. Advances in Remote Sensing, 4, $1-6$.

INOUE, T., 1987, A cloud type classification with NOAA-7 split window measurements. Journal of Geophysical Research, 92, 3991-4000. 
Justice, C. O., Kendall, J. D., Dowty, P. R., and Scholes, R. J., 1996, Satellite remote sensing of fires during the SAFARI campaign using NOAA advanced very high resolution radiometer data. Journal of Geophysical Research, 101, 23 851-23 863.

Kaufman, Y. J., Tucker, C. J., and Fung, I., 1990, Remote sensing of biomass burning in the tropics. Journal of Geophysical Research, 95, 9927-9939.

Kennedy, P. J., Belward, A. S., and Gregoire, J.-M., 1994, An improved approach to fire monitoring in West Africa using AVHRR data. International Journal of Remote Sensing, 15, 2235-2255.

Levine, J. S. (ed.), 1991, Global Biomass Burning: Atmospheric, Climatic, and Biospheric Implications (Cambridge, Massachusetts: MIT Press).

Levine, J. S., Cofer, W. R., III, Cahoon, D. R., JR, and Winstead, E. L., 1995, Biomass burning: a driver for global change. Environmental Science and Technology, 29, 120-125.

Li, Z., Cihlar, J., Moreau, L., Huang, F., and Lee, B., 1997, Monitoring fire activities in the boreal ecosystem. Journal of Geophysical Research, 102, 29 611-29624.

Li, Z., Nadon, S., Cihlar, J., and Stocks, B., 2000, Satellite mapping of Canadian boreal forest fires: evaluation and comparison of algorithms. International Journal of Remote Sensing, 21, 3071-3082 (this issue).

Malingreau, J. P., 1990, The contribution of remote sensing to the global monitoring of fires in tropical and subtropical ecosystems. In Fire in the Tropical Biota, edited by J. G. Goldammer, Ecosystem Processes and Global Challenges, Ecological Studies (Berlin: Springer), pp. 337-370.

Pokrant, H., 1991, Land cover map of Canada derived from AVHRR images. Manitoba Remote Sensing Centre, Winnipeg, Manitoba, Canada.

Rao, C. R. N., and Chen, J., 1996, Post-launch calibration of the visible and near-infrared channels of the Advanced Very High Resolution Radiometer on NOAA-14 spacecraft. International Journal of Remote Sensing, 17, 2743-2747.

Robertson, B., Erickson, A., Friedel, J., Guindon, B., Fisher, T., Brown, R., Teillet, P., D'Iorio, M., Cihlar, J., and SAncz, A., 1992, GEOCOMP, a NOAA AVHRR geocoding and compositing system. Proceedings of the ISPRS Conference, Commission 2, Washington, DC (Washington: ISPRS), pp. 223-228.

Robinson, J. M., 1991, Fire from space: global fire evaluation using infrared remote sensing. International Journal of Remote Sensing, 12, 3-24.

Scholes, R. J., 1995, Greenhouse gas emissions from vegetation fires in Southern Africa. Environmental Monitoring and Assessment, 38, 169-179.

Sellers, P. J., Hall, F. G., Margolis, H., Kelly, B., Baldocchi, D., DenHartog, J., Cihlar, J., Ryan, M., Goodison, B., Crill, P., Ranson, J., Lettenmaier, D., and Wickland, D. E., 1995, The Boreal Ecosystem-Atmosphere Study (BOREAS): an overview and early results from 1994 field year. Bulletin of American Meteorological Society, 76, 1549-1577.

Setzer, A. W., and Malingreau, J. P., 1996, AVHRR monitoring of vegetation fires in the tropics: toward the development of a global product. Biomass Burning and Global Change, edited by J. S. Levine (MIT Press: Cambridge, Massachusetts), pp. 25-39.

Setzer, A. W., and Verstraete, M. M., 1994, Fire and glint in AVHRR's channel 3: a possible reason for the non-saturation mystery. International Journal of Remote Sensing, 15, 711-718.

SingH, K. D., 1993, The 1990 tropical forest resource assessment, Unasyva/FAO, 44, 10-19. 